\title{
Turismo enfocado a campos de concentración: el caso de Auschwitz-Birkenau. Recordar la historia para no repetirla
}

\author{
Francisca Ramón Fernández | Dpto. de Urbanismo, Universitat Politècnica de València \\ URL de la contribución <www.iaph.es/revistaph/index.php/revistaph/article/view/5018>
}

Turismo negro, oscuro, macabro, tétrico, de horror. ¿Qué motiva al turista a visitar estos espacios?

Una de las preguntas que nos formulamos es qué puede motivar a un turista a visitar lugares donde se ha producido un sufrimiento humano. Posiblemente podamos hablar de curiosidad, del morbo añadido de ver lugares donde ha ocurrido una masacre, asesinatos, crímenes que han saltado a los medios de comunicación o hechos luctuosos. Se trataría de de una tipología de turista que se siente atraído por lugares o sitios que muestran el lado más cruel de la especie humana.

Uno de esos lugares son los campos de concentración. Y, posiblemente, la atracción por visitar este tipo de sitios deriva de la influencia cinematográfica. Por ejemplo, en el caso de Auschwitz-Birkenau, la película La lista de Schindler incrementó el turismo en el campo de concentración, siendo actualmente la Deutsche
Emailwarenfabrik, también conocida como la Fábrica de Oskar Schindler, uno de los lugares más visitados en Cracovia. Sin embargo, el tratamiento de la memoria del Holocausto es muy diferente en la visita de la fábrica y en el museo del campo de concentración.

No podemos establecer un paralelismo entre los campos de concentración y los cementerios, otro caso recurrente que se menciona cuando se habla de un turismo "diferente", de ese turismo negro o Dark tourism. El turismo de cementerios se orienta a la visita de los camposantos en los que están enterradas personas famosas o célebres, y también es atraído por del patrimonio funerario, ya que algunas de las tumbas y panteones son auténticas obras de arte, realizadas por escultores de renombre. La visita se interpreta como muestra de admiración y respeto. Cosa que no sucede en el caso de los campos de concentración.

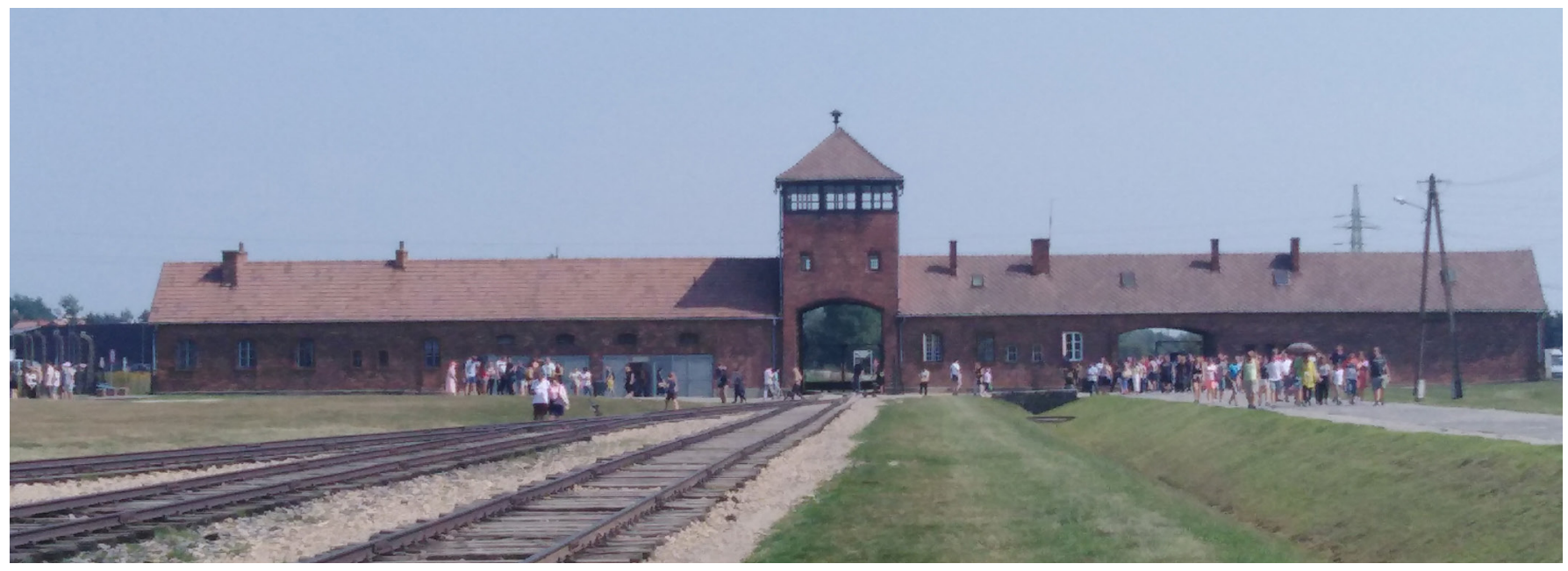

Llegada al campo de concetración | foto todas las imágenes que ilustran esta contribución son de Francisca Ramón Fernández 


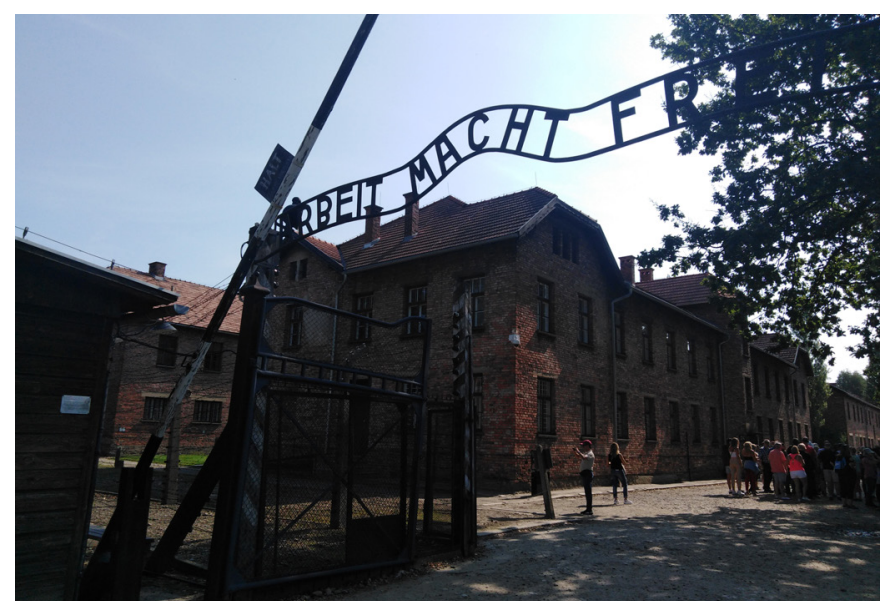

Entrada al campo

En esta aportación, se va a realizar una reflexión sobre lo que constituyó mi visita al campo de concentración de Auschwitz-Birkenau motivada por ver el tratamiento que hacía, de los hechos que allí ocurrieron, un lugar que se ofrece como "atractivo turístico", así como de los elementos mostrados en la visita, y el comportamiento del turista que recorre dicho espacio, un lugar que representa el paradigma del mal (González y Mundet 2018). La visita se realizó durante el mes de agosto del año 2019, y fue acompañada de una guía.

El campo de concentración Auschwitz-Birkenau, Oświęcim, Polonia: todo menos un lugar de homenaje a la memoria de las víctimas del Holocausto nazi Los campos de concentración, como el de AuschwitzBirkenau, convertidos en lugares para "remover conciencias" no consideramos que traduzcan en un homenaje a las víctimas del Holocausto, según se muestra en la actualidad. El campo de concentración y exterminio más importante de la Segunda Guerra Mundial, en el que se acabó con la vida de miles de inocentes, se abrió a la visita pública en el año 1947, fue declarado Patrimonio Mundial por parte de la UNESCO en el año 1979 (Castro y Wójtowicz 2018), y es objeto de numerosas visitas cada año (Lozano y Malerba 2017).

Este campo de concentración, como otros, se ha convertido en un lugar de atracción turística, pero no habría que

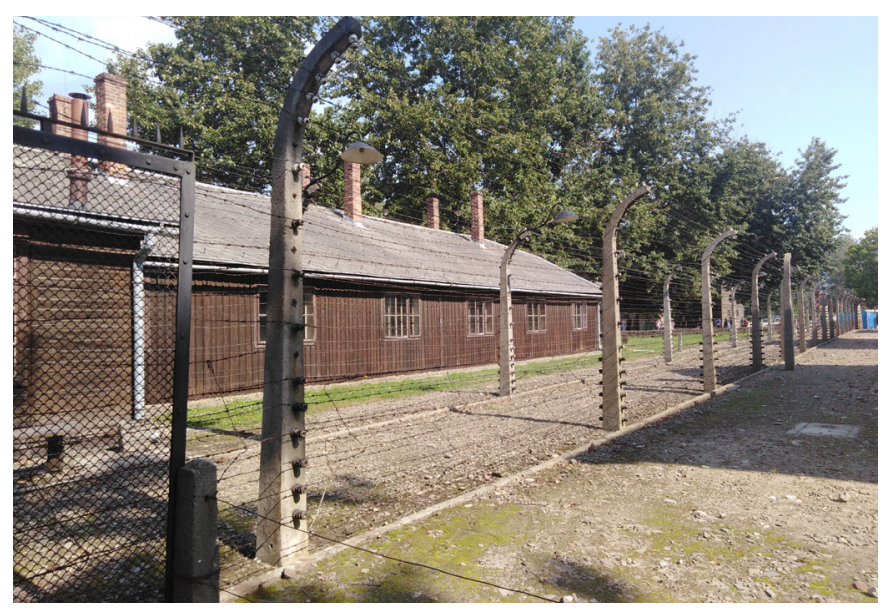

Alambradas

olvidar que es el escenario de una de la mayores tragedias de muertes masivas (Castro y Wójtowicz, 2018). Llama la atención que el turista, lejos de mostrar una actitud respetuosa durante la visita, parece centrar su interés en "hacer fotos": desde la entrada principal, con captura de su propia imagen junto a la inscripción Arbeit Macht Frei (el trabajo los hará libres) en el arco superior; pasando por las alambradas electrificadas; las vías del tren de llegada al campo de Birkenau; el interior de los barracones; e incluso dentro de las cámaras de gas. Con la posterior exposición en redes sociales de todos estos selfies, haciendo alarde de haber estado allí, como si la satisfacción de la visita estuviera concentrada en la toma de imágenes.

Se trata de lugares que recuerdan el horror sufrido, y que ahora son contemplados con un ánimo de divertimento, incluso con la finalidad de tener una experiencia "diferente". Consideramos que también es una falta de respeto la exhibición que se realiza de objetos personales, y la permisión de la toma de imágenes en todo momento durante la visita al campo de concentración. Tan solo se prohíbe hacer fotografías en la sala donde se encuentran restos del cuerpo humano, como por ejemplo, el pelo, que se muestra a través de las cristaleras, produciendo una impresión totalmente espeluznante.

La visita al campo de concentración se ha convertido en un producto de consumo turístico, con un interés lucra- 


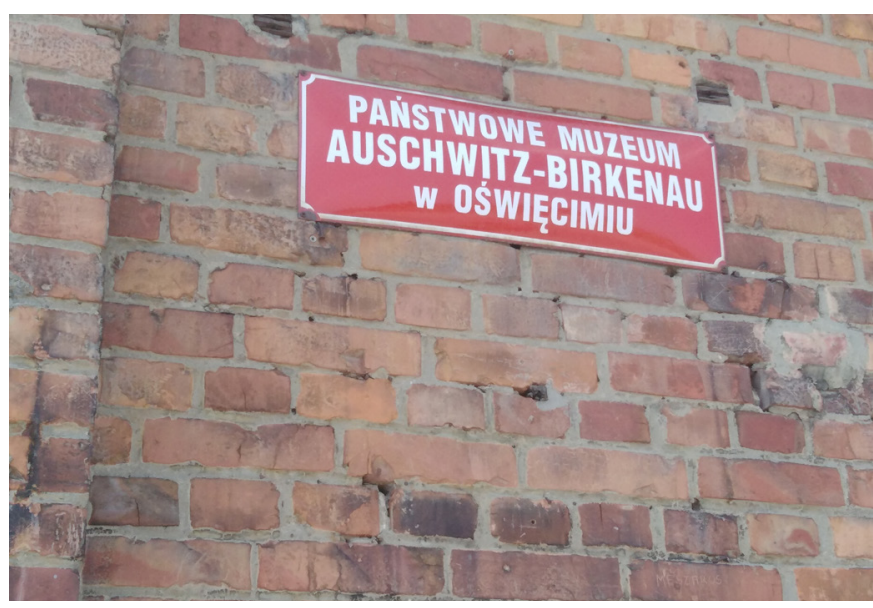

Señalética del museo

tivo, que exhibe sin pudor efectos personales de las víctimas (zapatos, ropa, equipaje, utensilios de aseo, de cocina, entre otros) sin ningún tipo de propuesta interpretativa para el visitante. Junto a los objetos, se establecen galerías con las imágenes de las víctimas en una suerte de feria de los horrores, en las que se atenta contra la dignidad de la persona.

Si la intención del lugar era ofrecer un memorial en recuerdo de las víctimas se hubiera tenido que realizar con otros elementos, y con la supresión de los objetos personales, que solo añaden morbo al sufrimiento que allí se muestra. Parece que no se hubieran establecido límites en la exposición del sufrimiento y del horror, y se produce una exhibición gratuita y no justificada del padecimiento.

La visita, que tiene una larga duración, y en la, posteriormente, que se traslada al turista de Auschwitz, al campo de Birkenau, se percibe como un itinerario por la atrocidad y horror, ya que se muestran y se pueden visitar los barracones, siendo especialmente impactante el destinado a los niños, en el que todavía se aprecian las ilustraciones escolares en las paredes.

Precisamente uno de los aspectos que más llaman la atención es que no se prohíbe la entrada a menores, solo se indica que "no se recomiendan las visitas al Museo de niños menores de 14 años", también en su página web.

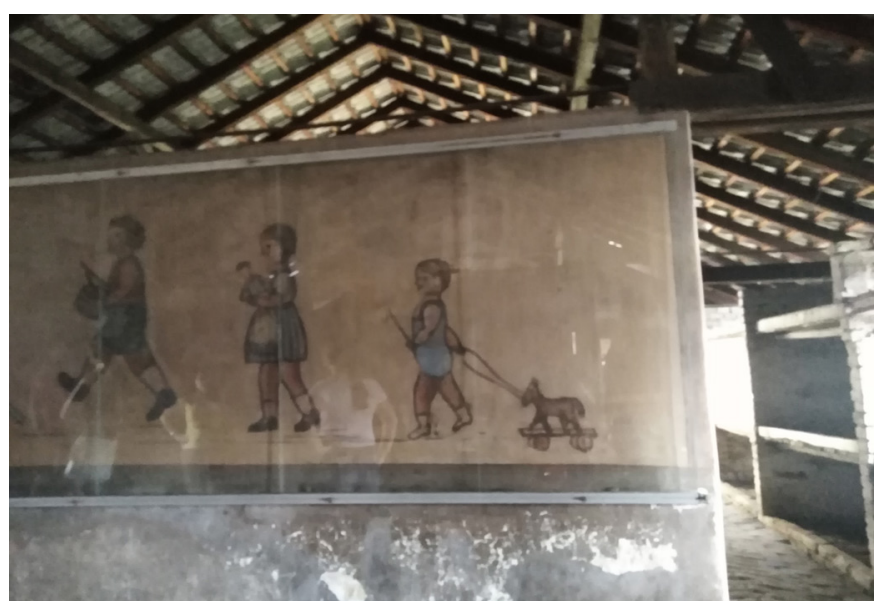

Barracones de los niños

Consideramos que la visita debería estar restringida a las personas mayores de edad, porque para los menores puede resultar de gran impacto emocional o, en ocasiones, ajenos de los que el recorrido muestra, fomentar en ellos un comportamiento irrespetuoso.

Opinamos que el turista se comporta como si se encontrara ante un "parque temático" de la guerra, de un horror generalizado, en el que se "olvida" lo acontecido. Se habla de disneylización en los tours que se ofrecen para pasar el día en los campos de concentración. No podemos olvidar que lo que estamos visitando es un campo de muerte, un campo en el que murieron miles de personas, y en el que se violaron todos los derechos humanos. Es totalmente irreverente su consideración como sitio turístico. Debía el turista comportarse con una actitud de recogimiento, de conciencia, y no hacerlo como en un lugar de disfrute (Naef 2014).

\section{Reflexión final}

La necesidad de establecer límites en la exhibición del dolor humano y del sufrimiento debe ser contemplada a la hora de mostrar un "lugar de la memoria" como es el Museo Estatal Auschwitz-Birkenau.

La exhibición de objetos personales, imágenes, utensilios, e incluso de partes del cuerpo humano, resulta en un museo del horror que se aleja de un pretendido 
a debate Interpretación y gestión del patrimonio en los espacios del turismo oscuro

| coordinan Óscar Navajas Corral y Maribel Rodríguez Achútegui

homenaje, y que supone un incremento del morbo del visitante, sin ninguna otra valoración.

El turista parece encontrarse en un "parque temático" del horror y percibe el dolor como una atracción turística, descontextualizado e incluso como "imaginado", como si los acontecimientos que se muestran no hubieran sucedido. De ahí que pueda comer, beber, reír, y "disfrutar" de la visita. E incluso comprar souvenirs, una muestra más de la comercialización del sufrimiento y una actividad lucrativa en aras de fomentar el turismo negro, ante la demanda del mismo por parte de un tipo de turista.

Se ha producido una auténtica transformación del lugar, lejos de su origen y totalmente distorsionada (Naef, 2014). Se banalizan los acontecimientos históricos y se sacraliza el Holocausto convirtiendo el lugar en un sitio eufémico de un horror que no se puede suavizar.

Nos preguntamos si esa oferta que se produce a través de agencias, en las que Auschwitz se asimila a actividades lúdicas como pueden ser una despedida de soltero, un paintball o incluso un striptease (Naef 2014), va más allá de un recinto que debe inspirar respeto y, sobre todo, no olvido de lo que allí ocurrió. No todo vale para obtener un lucro con lugares asociados a acontecimientos que han marcado a la humanidad. El consumismo de los lugares de horror es una realidad, y también es una distorsión de la propia realidad que ocurrió, ya que el visitante es guiado y orientado hacia lo "vendible" y ese posicionamiento no ayuda a la comprensión y reflexión de lo ocurrido (Neuraska 2013). El turista quiere más y más y el culmen de su visita es el crematorio, por supuesto, visitable y fotografiable, y todo ello está estratégicamente cuidado en el tour. El turista es un espectador, un voyeur (Neuraska 2013) que va devorando imágenes, espacios y objetos que se muestran, sin pararse ni siquiera a pesar que eso sucedió realmente, que no es ciencia ficción. De hecho, el turista tiene la opción de llevarse como recuerdo, múltiples objetos, a cuál más terrorífico, de su paso por el lugar. Ni qué decir tiene que dicho recuerdo no puede considerarse como turístico, precisamente.

\section{BIBLIOGRAFÍA}

- Castro Pérez, P. y Wójtowicz, M. (2018) Dibujando un sitio de atrocidad y tragedia: la percepción turística del "patrimonio difícil" del Museo de Auschwitz-Birkenau, Polonia. En: Alvarado Sizzo, I., López López, A, Godínez Calderón, L. y Casado Izquierdo, J.M ${ }^{a}$ (coord.) Turismo, patrimonio y representaciones espaciales. Santa Cruz de Tenerife: Pasos, pp. 257-288 (Colección Pasos, n. ${ }^{\circ}$ 22). Disponible en: http:// www.pasosonline.org/Publicados/pasosoedita/PSEdita22.pdf [Consulta: 21/10/2021]

- González Vázquez, D. y Mundet I Cerdán, LI. (2018). Lugares de memoria traumática y turismo: paradigmas analíticos y problemáticas. Investigaciones Turísticas, $\mathrm{n} .^{\circ}$ 16, pp. 108-126. Disponible en: https://rua.ua.es/dspace/ bitstream/10045/84550/1/Investigaciones-Turisticas_16_06. pdf [Consulta: 21/10/2021]

- Lozano, Z. y Malerba, R. (2017) Turismo sombrio: análise de satisfação dos visitantes do Museo Estatal AuschiwitzBierkenau com base em avaliações online. Revista Turismo \& Desenvolvimento, n. ${ }^{\circ}$. 27-28, 2, pp. 475-477. Disponible en: http://revistas.ua.pt/index.php/rtd/article/view/6897/5400 [Consulta: 21/10/2021]

- Museo Estatal Auschwitz-Birkenau. Disponible en: http:// auschwitz.org/en/more/spanish/ [Consulta: 21/10/2021]

- Naef, P. (2014) Disneylandisation des horreurs de la guerre. Visionscarto. Disponible en: https://visionscarto.net/ disneylandisation-guerre [Consulta: 27/10/2021]

- Neuraska, E. (2013) Auswitchpark. Herejía y belleza. Revista de estudios culturales sobre el movimiento gótico, $\mathrm{n} .{ }^{\circ}$ 1, 283-300. Disponible en: https://repositorio.uam.es/bitstream/ handle/10486/11863/58410_18.pdf?sequence=1 [Consulta: 27/10/2021]

\section{Agradecimientos}

Trabajo realizado en el marco del Proyecto $1+D+i$ «Retos investigación» RTI2018-097354-B-100 (2019-2022) Proyecto de I+D+i Retos MICINN PID2019-108710RB-I00 (2020-2022). 